TEMAS EMERGENTES

\title{
Estándares interamericanos sobre empresas y derechos humanos: Nuevas perspectivas para la conducta empresarial responsable en las Américas
}

\author{
Inter-American standards on business and human rights: \\ New perspectives for responsible business conduct in the Americas
}

\section{Daniel Iglesias Márquez \\ Universidad de Sevilla, España}

\begin{abstract}
RESUMEN En los últimos años, la cuestión sobre empresas y derechos humanos en las Américas ha tenido una evolución significativa, debido a los diversos y constantes episodios de abusos de derechos humanos cometidos en el contexto de las actividades empresariales. Así, en una región dependiente, influenciada y azotada por las élites empresariales, han emergido acciones e iniciativas desde los Estados y las organizaciones regionales en las que se promueve una conducta empresarial responsable. El presente artículo tiene como objetivo reflexionar y analizar el alcance, el contenido y las aportaciones novedosas del informe de la Comisión Interamericana de Derechos Humanos en materia de empresas y derechos humanos de 2020, que contiene y desarrolla los mínimos estándares de conducta exigibles a los Estados - y a las empresas- para respetar y garantizar el disfrute de los derechos humanos en el contexto de las actividades empresariales.
\end{abstract}

PALABRAS CLAVE Empresas, derechos humanos, estándares, Sistema Interamericano de Derechos Humanos, América.

ABSTRACT The issue of business and human rights in the Americas has significantly evolved over the last years due to the various and constant episodes of business-related human rights abuses. Thus, in a region reliant on, influenced and hit by business elites, actions and initiatives have emerged from States and regional organizations that promote responsible business conduct. The purpose of this article is to reflect and analyze the scope, content, and novel contributions of the 2020 report of the Inter-American Commission on Human Rights on business and human rights, which contains and develops the minimum standards for States - and business - to respect and guarantee the enjoyment of human rights in the context of business activities. 
KEYWORDS Businesses, human rights, standards, Inter-American Human Rights System, America.

\section{Introducción}

El marco institucional y jurídico de la economía-mundo capitalista estimula y beneficia el desarrollo de actividades empresariales, con graves impactos negativos sobre los derechos humanos y el medio ambiente. ${ }^{1}$ Esto ha planteado la progresiva necesidad de explorar y profundizar en la relación entre las empresas y los derechos humanos. En el seno de las Naciones Unidas, los Estados han debatido desde la década de 1970 sobre la responsabilidad de las empresas en el ámbito de derechos humanos e, incluso, han alcanzado importantes avances, como los Principios Rectores sobre empresas y derechos humanos, aprobados en 2011 por el Consejo de Derechos Humanos $(\mathrm{CDH})(\mathrm{A} / \mathrm{HRC} / 17 / 31)$, que rigen en la actualidad la agenda nacional e internacional en este ámbito. Los Principios Rectores, junto con otros instrumentos no vinculantes de carácter general, marcan el punto de partida para el actuar de los Estados y las empresas en esta materia. Después estos actores deberán adoptar las medidas necesarias para aplicarlos según las necesidades y particularidades de contextos específicos.

Por ello, los debates en el ámbito de empresas y derechos humanos se han trasladado a nivel regional - e incluso a nivel nacional - para atender de manera concreta los retos y las necesidades particulares de asegurar una conducta empresarial responsable según el contexto económico, jurídico, político y cultural del que se trate. Por ejemplo, el continente americano es un destino atractivo para el desarrollo de proyectos y actividades empresariales de gran envergadura para la economía-mundo capitalista, ya que muchos de sus Estados disponen de los recursos naturales y la mano de obra necesaria, así como de las políticas económicas favorables para que las empresas de la región y extranjeras lleven a cabo sus operaciones. Sin embargo, los Estados cuentan, al mismo tiempo, con grupos de población en situación de vulnerabilidad (pueblos indígenas, personas viviendo en situación extrema de pobreza, etcétera), altos niveles de corrupción y sistemas regulatorios laxos, entre otras cuestiones, que potencian los impactos negativos de las actividades empresariales sobre los derechos humanos y el medio ambiente.

Por lo anterior, en los últimos veinte años los Estados del continente y su principal organización regional, la Organización de los Estados Americanos (OEA), han profundizado de manera progresiva en la cuestión sobre empresas y derechos humanos. ${ }^{2}$

\footnotetext{
1. Sobre la economía-mundo capitalista, véase Wallerstein (2005: 40-51).

2. Para un panorama general de las cuestiones y debates en materia de empresas y derechos humanos en las Américas, véase Cantú Rivera (2017a).
} 
Desde el continente han emergido propuestas interesantes en la materia, como la liderada por Ecuador, junto con Sudáfrica, de adoptar un tratado que regule la prevención y reparación de los abusos de derechos humanos cometidos por empresas. ${ }^{3}$ Asimismo, en la región, el papel de los dos órganos principales del Sistema Interamericano de Derechos Humanos (SIDH), la Comisión Interamericana (CIDH) y la Corte Interamericana de Derechos Humanos (Corte IDH) ha sido clave para que los Estados avancen en la materia a la luz de sus obligaciones contenidas en los instrumentos interamericanos de derechos humanos. Históricamente, ambos órganos, en el ejercicio de sus competencias y en relación con la doctrina de la Drittwirkung, han abordado de manera directa o indirecta cuestiones relativas al ámbito de empresas y derechos humanos. ${ }^{4}$

El presente artículo tiene como objetivo exponer y examinar los estándares identificados y desarrollados en el informe de la CIDH, titulado «Empresas y derechos humanos: Estándares interamericanos», publicado a inicios de 2020. Para ello, en primer lugar, se hace una retrospectiva sobre la evolución de la cuestión de empresas y derechos humanos en el seno de la OEA y sus distintos órganos. En segundo lugar, se explora y analiza críticamente la naturaleza jurídica y el contenido del informe. En tercer lugar, se exponen algunas de las principales novedades y aportaciones que ofrece el SIDH al debate universal y regional de empresas y derechos humanos a través del informe analizado. Por último, se ofrecen algunas consideraciones finales.

\section{Evolución histórica de la responsabilidad empresarial en el seno de la Organización de los Estados Americanos y sus órganos}

La responsabilidad de las empresas de respetar los derechos humanos y proteger al medio ambiente no es una cuestión novedosa en el seno de la OEA y sus diferentes órganos - políticos y consultivos-que la componen. Desde el año 2001, la Asamblea General de la OEA ha adoptado diversas resoluciones que debaten y promueven una conducta empresarial responsable (Salazar, 2015: 9-11; Villalta Vizcarra, 2020: 191-192). La Resolución 1.786 (XXXI-O/o1), sobre la Promoción de la Responsabilidad Social de las Empresas en el Hemisferio, marcó un importante punto de partida, ${ }^{5}$ ya que encomendó al Consejo Permanente de la OEA el análisis de la responsabilidad social de las empresas, con el fin de precisar su alcance y contenido dentro del contexto interamericano. A partir de entonces, esta cuestión ha formado parte de la agenda

3. Sobre el tratado en materia de empresas y derechos humanos, véase Iglesias Márquez (2019a).

4. Véase la sentencia del caso Velásquez Rodríguez con Honduras, Corte Interamericana de Derechos Humanos, fondo, 29 de julio de 1988, serie C núm. 4.

5. Organización de los Estados Americanos, AG/RES 1.786 (XXXI-O/o1), Promoción de la Responsabilidad Social de las Empresas en el Hemisferio, 5 de junio de 2001. 
de trabajo de la OEA, con miras a que las empresas de la región lleven a cabo sus operaciones de forma congruente con sus responsabilidades sociales y ambientales.

La OEA se ha mostrado abierta al diálogo sobre la responsabilidad empresarial no sólo entre los Estados miembros, sino también con otras organizaciones internacionales y regionales capaces de influir en el comportamiento de las empresas. En este sentido, la Resolución 1.871 (XXXII-O/o2) solicitó al Consejo Permanente que fomentara el intercambio de experiencias e información entre la OEA, otras organizaciones multilaterales, instituciones financieras internacionales, el sector privado y la sociedad civil, entre otros actores pertinentes, con el fin de coordinar y fortalecer las actividades de cooperación en el área de la responsabilidad social de las empresas. ${ }^{6}$

Por otra parte, en el seno de la OEA se ha instado a los Estados miembros a que apoyen los programas e iniciativas de promoción de la responsabilidad social de las empresas a través de principios y lineamientos reconocidos internacionalmente. Por ejemplo, las Resoluciones 2.123 (XXXV-O/05), 2.194 (XXXVI-O/o6), 2.336 (XXXVIIO/o7) y 2.483 (XXXIX-O/o9)7 exhortaban a los Estados miembros a promover el uso de directrices, herramientas y prácticas aplicables en materia de responsabilidad social de las empresas, incluyendo las Directrices para las Empresas Multinacionales de la Organización de Cooperación y Desarrollo Económicos, la Declaración Tripartita de Principios sobre las Empresas Multinacionales y la Política Social de la Organización Internacional del Trabajo (OIT), el Pacto Mundial de las Naciones Unidas, los Principios Voluntarios sobre Seguridad y Derechos Humanos y los principios contenidos en la resolución de la OIT sobre la Promoción de las Empresas Sostenibles, entre otros. Asimismo, se recomendaba a los Estados miembros que explotan activamente los recursos naturales a participar en la Iniciativa para la Transparencia en las Industrias Extractivas. ${ }^{8}$

La adopción de los Principios Rectores en 2011 influyó, sin duda, en la perspectiva de la Asamblea General, y de otros órganos de la OEA, sobre la responsabilidad de las

6. Organización de los Estados Americanos. AG/RES 187 (XXXII-O/o2), Promoción de la Responsabilidad Social de las Empresas en el Hemisferio, 4 de junio de 2002. En un sentido similar, véase, AG/ RES 1.953 (XXXIII-O/o3), y AG/RES 2.013 (XXXIV-O/o4), ambas resoluciones promueven el análisis, intercambio y divulgación de información y de los avances alcanzados por los Estados miembros en materia de responsabilidad empresarial.

7. Organización de los Estados Americanos, AG/RES 2.123 (XXXV-O/05), Promoción de la Responsabilidad Social de las Empresas en el Hemisferio, 7 de junio de 2005; AG/RES 2.194 (XXXVI-O/o6), Promoción de la Responsabilidad Social de las Empresas en el Hemisferio, 6 de junio de 2006; AG/RES 2.336 (XXXVII-O/07), Promoción de la Responsabilidad Social de las Empresas en el Hemisferio, 5 de junio de 2007; AG/RES 2.483 (XXXIX-O/o9), Promoción de la Responsabilidad Social de las Empresas en el Hemisferio, 4 de junio de 2009.

8. Sobre el desarrollo e implementación de estas iniciativas de responsabilidad empresarial en las Américas, véase Gos (2016). 
empresas de respetar los derechos humanos (Carrillo-Santarelli y Arévalo-Narváez, 2017: 76-97). Por ejemplo, la Resolución 2.753 (XLII-O/12), reconoció —en un lenguaje similar al de los Principios Rectores- que las empresas y otros actores sociales desempeñan un papel importante y comparten la responsabilidad de promover y respetar la observancia de los derechos humanos en el contexto de sus actividades. ${ }^{9}$ Dicha resolución puede considerarse como un primer paso en la evolución del enfoque de la agenda regional sobre la materia, ya que intenta alejarse de la filantropía de la responsabilidad social corporativa para asegurar que las empresas respeten los derechos humanos en sus operaciones a través de estándares articulados en el marco de las obligaciones y compromisos internacionales de los Estados. De esta manera, la perspectiva de la OEA sobre el tema de la responsabilidad empresarial se alineó con los avances y desarrollos alcanzados en el sistema universal de derechos humanos.

Tras la adopción de los Principios Rectores, la Asamblea General de la OEA no sólo adoptó la terminología y el lenguaje empleado en los Principios Rectores en sus resoluciones sobre la materia, sino que también redirigió los esfuerzos de los Estados a su promoción e implementación. En este sentido, solicitó a distintos órganos de la OEA que, en el ámbito de sus competencias y de manera coordinada, apoyaran el desarrollo de planes de acción nacionales sobre derechos humanos y empresas como una forma de implementar a nivel nacional los Principios Rectores. ${ }^{10}$

Un segundo paso importante en la evolución de la agenda sobre la responsabilidad empresarial en el seno de la OEA lo constituye la Resolución 2.887 (XLVI-O/16), ya que el tratamiento de esta cuestión profundiza en la visión regional. De esta manera, se promueve una conducta empresarial responsable que responda a las necesidades y características particulares de las Américas. Esto supone una mayor efectividad para asegurar el disfrute de los derechos humanos en el contexto de las actividades empresariales. Para ello, mediante la Resolución 2.887 , por un lado, se solicitó a la CIDH un estudio sobre los estándares interamericanos en materia de empresas y derechos humanos que sirviera de insumo para los Estados miembros. Esta petición dio lugar al informe que se analiza en los siguientes epígrafes y que debe ser considerado como un siguiente paso en la evolución de la agenda regional en la materia. Por otro lado, se encomendó al Comité Jurídico Interamericano, cuerpo consultivo de la OEA en asuntos jurídicos, una recopilación de buenas prácticas, iniciativas, legislación,

9. Organización de los Estados Americanos, AG/RES 2.753 (XLII-O/12), Promoción de la Responsabilidad Social de las Empresas en el Hemisferio, 4 de junio de 2012.

10. Véase, Organización de los Estados Americanos, AG/RES 2.840 (XLIV-O/14), Promoción y Protección de los Derechos Humanos en el Ámbito Empresarial, 4 de junio de 2014; AG/RES 2.887 (XLVI-O/16), Promoción y Protección de Derechos Humanos, 14 de junio de 2016; AG/RES 2.908 (XLVII-O/17), Promoción y Protección de Derechos Humanos, 21 de junio de 2017; AG/RES 2.928 (XLVIIIO/18), Promoción y Protección de Derechos Humanos, 5 de junio de 2018. 
jurisprudencia y desafíos, que pudiera ser utilizada como base para identificar alternativas en el tratamiento del tema. ${ }^{11}$

En suma, el debate sobre la relación entre las empresas y los derechos humanos tiene una larga trayectoria en la agenda de trabajo de la OEA y de los distintos órganos que la componen, aunque ha recibido un tratamiento cauteloso y pasivo. Esto explica, al menos en parte, que no se hayan adoptado instrumentos regionales de carácter vinculante que promuevan una conducta empresarial responsable como, por ejemplo, en el caso de Europa. La Unión Europea ha adoptado instrumentos que imponen obligaciones de diligencia debida o de divulgación de información a determinadas empresas que cumplan ciertas características o pertenezcan a un sector específico. ${ }^{12} \mathrm{Si}$ bien en el ámbito americano aún se está lejos de este tipo propuestas, no debe obviarse que el tema de empresas y derechos humanos ha tenido una importante evolución y un continuo desarrollo atendiendo a las necesidades y particularidades de la región.

\section{Estándares interamericanos en materia de empresas y derechos humanos}

Como se señaló, en 2016 la Asamblea General de la OEA solicitó a la CIDH un estudio sobre los estándares interamericanos en materia de empresas y derechos humanos (AG/RES. 2887 (XLVI-O/16)). La CIDH, en el ejercicio de su función de promover la observancia y la defensa de los derechos humanos y de servir como órgano consultivo de la OEA, ${ }^{13}$ ha contribuido con importantes aportaciones al debate sobre empresas y derechos humanos en la región de diferentes maneras, como a través del sistema de peticiones individuales, el otorgamiento de medidas cautelares $y$, no menos importante, de las más de 30 audiencias que ha celebrado sobre cuestiones de empresas y derechos humanos que ponen en evidencia la necesidad de avanzar en este tema desde una perspectiva regional (Gonza, 2016: 359). ${ }^{14}$

11. Véase, Organización de los Estados Americanos, AG/RES 2.887 (XLVI-O/16), Promoción y Protección de Derechos Humanos, 14 de junio de 2016.

12. En el ámbito de la Unión Europea se consolida cada vez más la propuesta de adoptar una normativa europea de diligencia debida en materia de derechos humanos y medio ambiente. En este sentido, la Comisión Europea ha anunciado su intención de discutir en el seno de la Unión una iniciativa legislativa para imponer a las empresas obligaciones de prevenir abusos de derechos humanos y daños ambientales a lo largo de su cadena de suministro. Véase, «Introductory remarks by commissioner Phil Hogan at OECD Global Forum on Responsible Business Conduct», Consejo de Europa, 19 de mayo de 2020, disponible en https://bit.ly/2IvxxCr.

13. Véase el artículo 41 de la Convención Americana y artículo 1 del Reglamento de la CIDH.

14. Por ejemplo, Estados, empresas y derechos humanos en América del Sur 158, periodo de sesiones, 7 de junio de 2016; Derechos humanos e industrias extractivas en Perú 162, periodo de sesiones, 25 de mayo de 2017; Empresas y derechos humanos en las Américas 172, periodo de sesiones, 8 de mayo de 2019; entre otras. 
La CIDH, a raíz del plan estratégico 2017/2021 (CIDH, 2017: 35-36), puso en marcha en 2017 la Relatoría Especial sobre Derechos Económicos, Sociales, Culturales y Ambientales (Redesca), ${ }^{15}$ con un mandato que implicaba avanzar en el tema de las empresas nacionales y transnacionales y sus impactos sobre los derechos humanos para desarrollar los estándares interamericanos al respecto (CIDH, 2017: 36). En cumplimiento de la petición de la Asamblea General, la CIDH encomendó el estudio sobre los estándares interamericanos en materia de empresas y derechos humanos a la Redesca.

Para la elaboración del informe, la Redesca se basó en el diálogo y la colaboración con múltiples actores de la región (Estados, sociedad civil, academia y otros actores interesados), a través de la organización y participación en talleres, eventos, reuniones de trabajo, audiencias públicas y consultas de expertos (CIDH, 2019: párrs. 33-37). En este punto, la Redesca destacó el alto nivel de interés y participación en torno al informe, lo que puso en evidencia la relevancia y transversalidad de la cuestión de empresas y derechos humanos en la región, así como la necesidad de un entendimiento común de la temática de acuerdo con los sistemas políticos, jurídicos, económicos y culturales de los Estados americanos.

El informe «Empresas y derechos humanos: Estándares interamericanos» de la CIDH y su Redesca sistematiza y analiza diversos pronunciamientos que se han dado dentro del SIDH en relación con el tema. El principal objetivo del informe es esclarecer el contenido de las obligaciones de los Estados, según los principales instrumentos interamericanos, en particular la Convención Americana sobre Derechos Humanos y la Declaración Americana de Derechos y Deberes del Hombre, la jurisprudencia interamericana y la inclusión articulada de avances internacionales en esta materia. Por ende, el informe busca identificar y desarrollar estándares interamericanos que coadyuven al cumplimiento de las obligaciones de los Estados. Al mismo tiempo, estos estándares deben servir para empoderar a las personas, comunidades y sindicatos para el uso de los instrumentos jurídicos y estándares interamericanos en este ámbito, fortalecer las acciones de diligencia debida en el contexto de las actividades empresariales, aumentar la rendición de cuentas ante abusos de derechos humanos en estos contextos y mejorar el acceso a reparaciones para las víctimas en este ámbito (CIDH, 2019: párrs. 28-29).

Se trata, sin duda, de un informe único en su clase en la región, ya que constituye una contribución sustancial para la discusión integral de la responsabilidad de las empresas en materia de derechos humanos y, sobre todo, para la configuración de iniciativas normativas y políticas, tanto a nivel regional como para los Estados. Sin

15. Tras el correspondiente concurso público interamericano, la CIDH designó como primera y actual Relatora DESCA a Soledad García Muñoz. Véase «Origen», Organización de los Estados Americanos, disponible en https://bit.ly/3oCtsM9. 
embargo, cabe matizar la naturaleza y los efectos jurídicos del informe y de los estándares identificados y desarrollados en éste.

En este sentido, el informe sobre empresas y derechos humanos de la CIDH y su Redesca no es resultado de su competencia cuasi jurisdiccional, que le permite examinar peticiones individuales relativas a violaciones de derechos humanos garantizados en la Declaración Americana, la Convención Americana y otros tratados interamericanos de derechos humanos. ${ }^{16}$ En el sistema de peticiones, la Comisión puede emitir informes que contienen su opinión, conclusiones finales y recomendaciones que considere necesarias respecto de los casos planteados. Por ejemplo, en el asunto Empleados de la Fábrica de Fuegos de Santo Antônio de Jesus con Brasil, la Comisión consideró responsable al Estado por la falta de fiscalización a una fábrica en la que sabía que se hacían actividades industriales peligrosas. Por tanto, recomendó al Estado, entre otras medidas, fortalecer sus instituciones para asegurar que cumplieran debidamente con su obligación de fiscalización e inspección de empresas que desarrollan actividades peligrosas mediante mecanismos adecuados de rendición de cuentas frente a autoridades que omitan el cumplimiento de dichas obligaciones. ${ }^{17}$

La naturaleza jurídica de los informes emitidos por la CIDH a partir del sistema de peticiones ha generado diversas discusiones doctrinales. Algunos autores atribuyen un carácter vinculante a estos informes, ya que reúnen las condiciones y formalidades para ser obligatorios y, sobre todo, porque son el resultado de un proceso con todas las garantías (Hitters, 2008: 136; O’Donnell, 1989: 490). No obstante, la opinión de la Corte IDH es que los informes de la Comisión en el sistema de peticiones no son vinculantes ni ejecutables, salvo que sus recomendaciones se incluyan en una sentencia. ${ }^{18}$ Esta controversia no afecta directamente al informe objeto de este artículo, en tanto que su función principal es recoger estándares preexistentes y avanzar en el desarrollo de otros. Por tanto, aunque carezca de efecto vinculante, su fuerza radica en su autoridad moral y política, debido a que contiene orientaciones que auxilian a los Estados y a los órganos del SIDH en la aplicación de los instrumentos interamericanos de derechos humanos en el contexto de las actividades empresariales.

En el SIDH, sus principales órganos se han encargado del establecimiento de estándares, con el fin de darle contenido a los derechos reconocidos en los instrumentos interamericanos. La CIDH define dichos estándares como «el conjunto de decisiones judiciales, informes temáticos y de país, y otras recomendaciones adoptadas por la [CIDH]» (CIDH, 2015a: 13). A su vez, añade que «el término "estándares jurídicos"

16. Véase el artículo 44 de la Convención y el artículo 23 del Reglamento de la CIDH.

17. Comisión Interamericana de Derechos Humanos, Informe de Fondo 25/18, Empleados de la Fábrica de Fuegos en Santo Antônio de Jesús y sus familiares (Brasil), 2 de marzo de 2018, párr. 176.

18. Véase la sentencia del caso Genie Lacayo con Nicaragua, fondo, reparaciones y costas, 29 de enero de 1997, serie C núm. 30, párr. 93. 
asimismo se refiere a los tratados regionales de derechos humanos que gobiernan el sistema interamericano, como la Convención Americana y la Convención de Belém do Pará. El concepto igualmente se refiere a las sentencias y opiniones consultivas emitidas por la Corte Interamericana de Derechos Humanos» (CIDH, 2015a: 13).

Por otra parte, reconoce que los estándares establecidos en el SIDH cumplen una función de guía para el actuar político de los Estados. En este sentido, la CIDH señala que los estándares «no solo tienen un importante valor como guía de interpretación de la Convención Americana para los tribunales nacionales, sino que pueden contribuir a mejorar la institucionalidad de las políticas y servicios sociales en los países americanos, y a fortalecer los sistemas de fiscalización, transparencia y rendición de cuentas, así como los mecanismos de participación y vigilancia social de las políticas públicas en esta materia» (CIDH, 2007: párr. 4).

Por lo anterior, los estándares establecidos y utilizados en el SIDH son catalogados como soft law, ya que únicamente orientan a los Estados en su actuar o en la construcción de su normativa y política pública interna con el fin de asegurar el ejercicio pleno de los derechos humanos (De Casas, 2019: 295). No obstante, la Comisión ha intentado dotarlos de fuerza vinculante, ya que considera que «el desarrollo jurídico de estándares en el marco del [SIDH] debe estar acompañado por esfuerzos de los Estados de ponerlos en práctica» (CIDH, 2015b: párr. 4). Sin embargo, en ocasiones, la amplitud de los estándares interamericanos genera dificultades en su interiorización en los sistemas nacionales y en las prácticas de los Estados (Molina Vergara, 2018: 246-252). La falta de incorporación de los estándares interamericanos en la legislación, políticas y prácticas de los Estados impide alcanzar la efectividad del SIDH. Al respecto, la Comisión ha manifestado su preocupación por la falta de incorporación de dichos estándares en países que no han ratificado los instrumentos interamericanos de derechos humanos (CIDH, 2015b: párr. 39).

En definitiva, aunque el informe «Empresas y derechos humanos: Estándares interamericanos» no es vinculante ni ejecutable, recopila y desarrolla valiosos estándares que buscan impactar en los sistemas políticos y jurídicos de los Estados, con el fin de alcanzar la operatividad efectiva de las normas del SIDH en el contexto de las actividades empresariales. En otros ámbitos, los estándares del Sistema han guiado las políticas de los Estados en beneficio de los derechos de las mujeres, los niños, las niñas y los pueblos indígenas (CIDH, 2015b: párr. 44). Por tanto, el informe aporta insumos relevantes para orientar la actuación de los Estados en este ámbito, así como para diseñar una hoja de ruta para un plan regional sobre empresas y derechos humanos, que incluya la adopción de instrumentos y políticas que respondan a las características y necesidades de los Estados americanos de conciliar el desarrollo económico con el respeto de los derechos humanos. ${ }^{19}$

19. Sobre la propuesta de un plan regional en la materia en el seno de la OEA, véase Cantú Rivera (2018). 


\section{Las obligaciones de los Estados en el contexto de las actividades empresariales a la luz de los estándares interamericanos}

El informe de la CIDH y su Redesca constituye un importante avance en la identificación y entendimiento de los mínimos exigibles a los Estados americanos para el cumplimiento de sus obligaciones de derechos humanos en el contexto de las actividades empresariales. En principio, se identifica la intención de esclarecer no sólo el contenido de las obligaciones que emanan de la Convención Americana, sino también de la Declaración Americana, considerada en el SIDH como una fuente de obligaciones jurídicas para los Estados miembros de la OEA. ${ }^{20}$ De esta manera, se promueve la incorporación de los estándares interamericanos sobre empresas y derechos humanos en la legislación, políticas y prácticas de países como Estados Unidos y Canadá, que no han ratificado la Convención Americana, pero cuyas empresas han generado impactos negativos sobre los derechos humanos y el medio ambiente en la subregión de América Latina. ${ }^{21}$ No obstante, la lectura y el análisis del informe permiten observar que la CIDH y su Redesca identifican y desarrollan los estándares interamericanos en esta materia, principalmente, a partir de las obligaciones erga omnes de respetar y garantizar los derechos humanos contenidas en el artículo 1.1 de la Convención Americana.

\section{La obligación de respetar en el contexto de las actividades empresariales}

La obligación de respetar consagrada en la Convención Americana implica la restricción al ejercicio del poder estatal. Es decir, «toda circunstancia en la cual un órgano o funcionario del Estado o de una institución de carácter público lesione indebidamente uno de tales derechos, se está ante un supuesto de inobservancia del deber de respeto». ${ }^{22}$ En el ámbito de empresas y derechos humanos, la CIDH y su Redesca señalan que esta obligación supone que «los Estados deban abstenerse de desplegar conductas vinculadas a actividades empresariales que contravengan el ejercicio de los derechos humanos» (CIDH, 2019: párr. 69). De lo contrario, la acción o inacción de las empresas puede dar lugar a la responsabilidad directa de los Estados por el incumplimiento de dicha obligación, sobre todo en los casos en los que existe un vínculo entre el Estado y las empresas implicadas en los abusos de derechos humanos. ${ }^{23}$

$\mathrm{LaCIDH}$ y su Redesca identifican tres supuestos que pueden generar la responsa-

20. Corte Interamericana de Derechos Humanos, Opinión Consultiva OC-10/89 del 14 de julio de 1989, serie A núm. 10, párrs. 35-45.

21. Sobre el impacto de las empresas canadienses en América Latina, véase, por ejemplo, Mijares Peña (2014) y DPLF (2014).

22. Caso Velásquez Rodríguez con Honduras, párr. 169.

23. Véase el comentario del Principio 5 de los Principios Rectores. 
bilidad directa de los Estados por la acción e inacción de las empresas: i) si la empresa ejerce atribuciones del poder público; ii) si la empresa está bajo la dirección y control del Estado; y iii) si el Estado reconoce y adopta como propio el comportamiento de la empresa. Aunque estos supuestos se recogen de las disposiciones 5, 8 y 11 de los Artículos sobre Responsabilidad del Estado por Hechos Internacionalmente Ilícitos, adoptados por la Comisión de Derecho Internacional de Naciones Unidas, tienen una relevancia importante en la región, ya que pueden aplicarse en el contexto de empresas públicas o con participación estatal mayoritaria, en la contratación pública de bienes y servicios y, por último, en la privatización de servicios públicos. Según se extrae del análisis de la jurisprudencia del SIDH, el comportamiento de las empresas en estos supuestos puede generar la responsabilidad de los Estados, al mismo tiempo que representan ámbitos de oportunidad para promover una conducta empresarial responsable, ya que los Estados tienen una mayor capacidad de influir en el comportamiento de las entidades empresariales.

Las empresas públicas, en especial las del sector extractivo y de hidrocarburos, son agentes económicos con un papel importante en la región y, por tanto, deben predicar con el ejemplo del ejercicio de las prácticas de diligencia debida en materia de derechos humanos, como se indica en los Principios Rectores. ${ }^{24}$ Incluso, se reconoce que la estrecha relación entre una empresa pública y el Estado supone que el comportamiento de estas empresas se rija directamente por las obligaciones internacionales de derechos humanos de prevenir y, en su defecto, reparar violaciones de derechos humanos (Schönsteiner, 2019: 900-901).

Algunas de las empresas públicas de América Latina no sólo han expandido sus actividades a lo largo de la región, sino que también mantienen relaciones comerciales con otras entidades privadas implicadas en abusos de derechos humanos. En estos casos, se intuye que los Estados disponen de un mayor nivel de influencia y control del comportamiento de las empresas públicas, ya que tienen una participación significativa en la toma de decisiones y en el financiamiento de sus actividades (Backer, 2017). Por tanto, la obligación de respetar se hace más estricta para los Estados cuando se trata de empresas públicas. En este sentido, según la opinión de la CIDH:

Cuando los proyectos extractivos, de explotación o desarrollo, se realizan por parte de empresas administradas por el Estado, se requiere llevar a cabo estrictas tareas de supervisión y fiscalización por parte de entidades que cuenten con las garantías mínimas de independencia e imparcialidad, con las competencias necesarias para verificar el respeto a los derechos humanos en estos contextos y actuar frente a su vulneración (CIDH, 2015c: párr. 101).

24. Véase, Consejo de Derechos Humanos, «Informe del Grupo de Trabajo sobre la cuestión de los derechos humanos y las empresas transnacionales y otras empresas», A/HRC/32/45, 4 de mayo de 2016, párrs. 74-77. 
En relación con la contratación pública, el Estado es el mayor demandante de bienes y servicios en la economía y, por tanto, no son pocos los casos en los que los Estados adquieren bienes y servicios de empresas privadas que pueden estar implicadas en abusos de derechos humanos (Morris, 2020: 9). Para determinar la responsabilidad directa del Estado en estos supuestos, se debe considerar si el comportamiento de la empresa responde a las instrucciones o al control efectivo del Estado (CIDH, 2019: párr. 72). Como bien expone Cantú Rivera (2020: 16), en el contexto de la contratación pública, los Estados gozan de una posición de superioridad que les permite imponer a las empresas las condiciones necesarias para asegurar que se respeten los derechos humanos en el desarrollo de sus actividades. Para ello, pueden establecer cláusulas contractuales que determinen obligaciones jurídicas concretas de identificación y prevención de riesgos en materia de derechos humanos.

La utilización de cláusulas contractuales contribuye a que los Estados cumplan con su obligación de respetar los derechos humanos en el contexto de las actividades empresariales. En este sentido, la CIDH y su Redesca recomiendan, en línea con el Principio Rector 5, que

los Estados pueden imponer directamente ciertas normas de conducta a los actores empresariales en contextos determinados; por ejemplo, en la contratación pública $[\ldots]$ que efectivamente puede exigir, y en su caso, cambiar cierta conducta o comportamiento del actor empresarial en correspondencia al cumplimiento de ciertos estándares en materia de derechos humanos (CIDH, 2019: párr. 164).

La consolidación de una práctica habitual de los Estados de incluir cláusulas de respeto de los derechos humanos en los contratos públicos tiene el potencial de generar a largo plazo cambios en el comportamiento de las empresas de determinados sectores en beneficio del respeto de los derechos humanos y de la protección del medio ambiente (Cantú Rivera, 2020: 16).

En la región también abundan casos en los que los Estados facultan a empresas privadas a ejercer atribuciones del poder público. El neoliberalismo en América Latina dio lugar a un importe proceso de privatización de servicios públicos con una regulación muy laxa. Esto permitió la participación de empresas privadas y la creación de asociaciones público-privadas en la provisión de servicios básicos, que son imprescindibles para el disfrute de los derechos humanos (Solanes, 1995: 158-161). La experiencia de la privatización de los servicios públicos en América Latina dio lugar a diversos conflictos entre el interés público y los objetivos de las empresas privadas, ${ }^{25}$ en los que suelen primar los intereses empresariales, según advierte la CIDH y su Redesca (2019: párr. 220). Ante tal situación, la Corte IDH señala que

25. Para un panorama de la luchas sociales y sindicales en contra de la privatización de servicios públicos en América Latina, véase Hernández Zubizarreta y otros (2013). 
si bien los Estados pueden delegar [la prestación de servicios públicos] la delegación a la iniciativa privada de proveer esos servicios, exige como elemento fundamental la responsabilidad de los Estados en fiscalizar su ejecución, para garantizar una efectiva protección de los derechos humanos de las personas bajo su jurisdicción y para que los servicios públicos sean provistos a la colectividad sin cualquier tipo de discriminación, y de la forma más efectiva posible. ${ }^{26}$

Por lo tanto, la CIDH y su Redesca establecen que los Estados deben abstenerse de atribuir a las empresas privadas funciones de poder público, como es el caso de la prestación de servicios públicos (como el suministro de agua, electricidad, seguridad, salud, educación, entre otros), si no se cuentan con marcos regulatorios y políticas claras que aseguren que las empresas respetan los derechos humanos en juego. Asimismo, deben someter a las empresas implicadas a la plena rendición de cuentas de sus operaciones y a un examen riguroso bajo sistemas de vigilancia transparentes y eficaces, previendo sanciones efectivas y reparaciones adecuadas para los casos de incumplimiento (CIDH, 2019: párr. 232). De lo contrario, como advierte el comentario al Principio Rector 5, las consecuencias pueden ser perjudiciales para la reputación del propio Estado y conllevar problemas legales. ${ }^{27}$

Finalmente, en relación con la obligación de respetar en el contexto de las actividades empresariales, la CIDH y su Redesca advierten que los Estados transgreden este deber cuando la conducta - activa u omisiva - de los agentes estatales implica su aquiescencia, tolerancia o colaboración respecto del comportamiento de las empresas que constituya violaciones de derechos humanos ( $\mathrm{CIDH}$, 2019: párrs. 73-78). En este sentido, recuerdan la amplia jurisprudencia del SIDH, en la que se atribuye una responsabilidad directa al Estado por complicidad en las violaciones de derechos humanos cometidas por actores paramilitares y paraestatales. ${ }^{28}$

\footnotetext{
26. Sentencia del caso Ximenes Lopes con Brasil, Corte Interamericana de Derechos Humanos, 4 de julio de 2006, serie C núm. 149, párr. 96.

27. En Muelle Flores con Perú, la Corte IDH determinó la responsabilidad del Estado por la falta de salvaguardias normativas para evitar violaciones al derecho a la seguridad social en procesos de privatización de una empresa estatal que crearon obstáculos para el cobro efectivo de las pensiones de un adulto mayor en Perú. Sentencia del caso Muelle Flores con Perú, Corte Interamericana de Derechos Humanos, excepciones preliminares, fondo, reparaciones y costas. 6 de marzo de 2019, serie C núm. 375, párr. 139.

28. Véase, por ejemplo, sentencia del caso 19 Comerciantes con Colombia, Corte Interamericana de Derechos Humanos, fondo, reparaciones y costas, 5 de julio de 2004, serie C núm. 109, párr. 135; sentencia del caso Yarce y otras con Colombia, excepción preliminar, fondo, reparaciones y costas, 22 de noviembre de 2016, serie C núm. 325, párr. 180 .
} 


\section{La obligación de garantizar en el contexto de las actividades empresariales}

La obligación de garantía en el artículo 1.1 de la Convención Americana implica que los Estados adopten las medidas apropiadas para proteger y preservar los derechos humanos reconocidos en ésta. Es decir, la obligación exige una acción positiva de los Estados, que no se agota con la existencia de un orden normativo dirigido a hacer posible su cumplimiento, sino que requiere, a su vez, una conducta gubernamental que asegure la eficaz garantía del libre y pleno ejercicio de los derechos humanos. ${ }^{29} \mathrm{La}$ obligación de garantía se proyecta más allá de la relación entre los agentes estatales y las personas sometidas a su jurisdicción, por lo que implica el deber de prevenir, en la esfera privada, que terceros vulneren los bienes jurídicos protegidos en el SIDH. ${ }^{3 \circ}$

La CIDH y su Redesca destacan que la obligación de garantizar tiene correspondencia con el Pilar 1 de los Principios Rectores sobre el deber de proteger los derechos humanos. Por tanto, los Estados deben adoptar las medidas apropiadas para prevenir, investigar, castigar y reparar abusos de derechos humanos cometidos en su territorio o su jurisdicción por terceros, incluidas las empresas. Para ello, la CIDH y su Redesca identifican y desarrollan cuatro deberes estatales interconectados para dar cumplimiento a la obligación de garantía en el contexto de las actividades empresariales: i) deber de prevenir violaciones a los derechos humanos en el marco de actividades empresariales; ii) deber de fiscalizar tales actividades; iii) deber de regular y adoptar disposiciones de derecho interno; $y$ iv) deber de investigar, sancionar y asegurar el acceso a reparaciones integrales para víctimas en dichos contextos (CIDH, 2019: párr. 86).

En cuanto al deber de prevenir, en el ámbito de empresas y derechos humanos este deber implica que las autoridades correspondientes de los Estados adopten las medidas oportunas para identificar y prevenir los impactos y riesgos, posibles y reales, de las actividades empresariales sobre los derechos humanos. Asimismo, supone que deben adoptar, o en su caso, requerir y asegurar que las empresas involucradas en dichos impactos y riesgos implementen medidas de corrección. Aunado a las medidas anteriores, los Estados deben fortalecer a las instituciones competentes para que puedan proporcionar una respuesta efectiva a dichos impactos y riesgos $(\mathrm{CIDH}$, 2019: párrs. 86 y 89 ).

Aunque no detallan una lista exhaustiva, la CIDH y su Redesca identifican algunas acciones que deben ser consideradas por los Estados para cumplir con el deber de prevenir. Por ejemplo, la adecuación de los marcos normativos para regular la

29. Caso Velásquez Rodríguez con Honduras, párr. 167.

30. Véase la sentencia del caso «Masacre de Mapiripán» con Colombia, Corte Interamericana de Derechos Humanos, 15 de septiembre de 2005, serie C núm. 134, párr. 111; y sentencia del caso Gonzales Lluy y otros con Ecuador, excepciones preliminares, fondo, reparaciones y costas, 1 de septiembre de 2015, serie C núm. 298. párr. 170. 
actuación de las empresas en el campo de los derechos humanos, la implementación de políticas de protección en casos de actividades empresariales riesgosas, la creación de estrategias para superar violaciones extendidas relacionadas con determinadas industrias o sectores económicos y la producción de estadísticas que permitan el diseño y la evaluación de las políticas públicas en la materia (CIDH, 2019: párrs. 90-95).

Por su parte, el deber de supervisar en el contexto de las actividades empresariales requiere el diseño y la implementación de mecanismos para dicho fin, según el tipo de actividad y la naturaleza de la empresa. La falta de supervisión de las actividades empresariales es un elemento común en diversos casos en el SIDH. Por ello, la CIDH y su Redesca hacen especial énfasis en el reforzamiento de las medidas de control y vigilancia de determinadas actividades propensas a afectar los derechos humanos y el medio ambiente, como los proyectos extractivos de recursos naturales y las actividades peligrosas. En este sentido, la CIDH y la Corte IDH se han pronunciado en diversas ocasiones sobre el deber de los Estados de fiscalizar las actividades empresariales bajo su jurisdicción..$^{31}$ En Kaliña y Lokono con Surinam, la Corte IDH subraya:

El Estado tiene el deber de proteger tanto las áreas de reserva natural como los territorios tradicionales con el fin de prevenir daños en el territorio indígena, inclusive aquél que proceda de terceros, a través de mecanismos adecuados de supervisión y fiscalización que garanticen los derechos humanos, en particular, mediante la supervisión y fiscalización de estudios de impacto ambiental. ${ }^{32}$

En relación con el deber de regular, la CIDH y su Redesca clarifican que en el ámbito de empresas y derechos humanos éste deber comprende la adopción de legislación interna y políticas pertinentes para la protección de los derechos humanos en el marco de la actividad empresarial de que se trate, lo que supone la incorporación de garantías sustantivas y procesales que aseguren el respeto a los derechos humanos en las disposiciones que regulan el comportamiento empresarial, incluyendo la creación, operación y disolución de las empresas (CIDH, 2019: párrs. 106-112).

La CIDH y su Redesca destacan algunos desarrollos adoptados en la región que cumplen con el deber de regular en el ámbito de empresas y derechos humanos. Por ejemplo, en Brasil, la Resolución 4.327/201433 dispone la obligación de las instituciones financieras de crear una política de responsabilidad social y ambiental. Asimismo, en Estados Unidos, la California Transparency in Supply Act ${ }^{34}$ de 2010 impone

31. Véase, por ejemplo, Corte Interamericana de Derechos Humanos, Opinión Consultiva OC-23/17, 15 de noviembre de 2017, serie A núm. 23, párrs. 154 y 163; CIDH, Informe de Fondo 40/04, Comunidades Indígenas Mayas del Distrito de Toledo, (Belice), 12 de octubre de 2004, párr. 147.

32. Sentencia del caso Pueblos Kaliña y Lokono con Surinam, Corte Interamericana de Derechos Humanos, fondo, reparaciones y costas, 25 de noviembre de 2015, serie C núm. 309, párr. 221.

33. Banco Central de Brasil, Resolução 4·327, 25 de abril de 2014.

34. California Transparency in Supply Chains Act of 2010, Civil Code Section 1714.43. 
a determinadas empresas la obligación de publicar en su sitio web un informe sobre las medidas adoptadas para erradicar la esclavitud moderna, tráfico de personas o trabajo forzado en sus filiales y cadenas de suministro. Si bien estos son avances importantes en la región, aún son escasos en comparación, por ejemplo, con Europa, donde hay una evidente tendencia al desarrollo normativo para garantizar el respeto de los derechos humanos en el contexto de las actividades empresariales (Iglesias Márquez, 2019b: 343-400).

El desarrollo normativo en Europa ha servido para avanzar progresivamente en la obligación de las empresas de implementar procesos de diligencia debida en derechos humanos, de conformidad con el Pilar 2 de los Principios Rectores. En Francia, por ejemplo, se aprobó la Loi relative au devoir de vigilance des sociétés mères et des entreprises donneuses d'ordre en 2017. La Loi de vigilance impone a las empresas que se encuentran bajo su ámbito de aplicación la obligación de elaborar y publicar un "plan de vigilancia» que incluya las medidas razonables orientadas a identificar los riesgos y prevenir violaciones de derechos humanos y daños ambientales, que resulten de sus actividades o de sus subcontratistas o proveedores con una relación comercial establecida. Otros desarrollos similares en Europa son la Modern Slavery Act de 2015 en el Reino Unido, la Directiva europea sobre divulgación de información no financiera y el Reglamento sobre los minerales de zonas de conflicto de la Unión Europea. En países como Suiza, Alemania, Australia, Bélgica y Finlandia, entre otros, se proponen iniciativas legislativas similares a las señaladas. ${ }^{35}$

No cabe duda de que los anteriores desarrollos normativos deben tenerse en cuenta por los Estados americanos al momento de diseñar sus propias medidas legislativas. No obstante, como señala Cantú Rivera, la legislación especializada en diligencia debida no es la única solución. El autor indica que la legislación que rige la creación y transformación de las sociedades mercantiles constituye un área desde la que se pueden plantear obligaciones generales de prevención, en la misma línea que los marcos normativos antes descritos. Por tanto, la adecuación de la legislación de sociedades

es de particular relevancia para países con sistemas normativos o regulatorios menos desarrollados, en virtud de que el incremento en la especificidad normativa debe coexistir de forma simultánea con la capacidad del Estado para supervisar efectivamente su cumplimiento, lo cual en muchas ocasiones termina siendo el elemento que conlleva a la violación de las obligaciones convencionales en materia de derechos humanos (Cantú Rivera, 2020: 14).

35. Para más información sobre el proceso y el contenido de las iniciativas de diligencia debida obligatoria en diversos Estados europeos, véase «National \& regional movements for mandatory human rights \& environmental due diligence in Europe», Business \& Human Rights Resource Centre, 22 de mayo de 2019, disponible en https://bit.ly/2Kw4yiR. 
Además del desarrollo normativo, la CIDH y su Redesca recomiendan que la legislación debe ir acompañada de políticas públicas que exijan el respeto de los derechos humanos por parte de los diferentes actores empresariales (CIDH, 2019: párr. 120). Al respecto, destacan la estrategia de algunos Estados de la región, como Colombia, Estados Unidos y Chile, de elaborar y adoptar Planes de Acción Nacional (PAN) sobre empresas y derechos humanos. ${ }^{36}$ Los PAN son instrumentos de política pública que hacen un balance de las acciones necesarias para aplicar los Principios Rectores $\mathrm{y}$, a su vez, determinan los ámbitos que requieren de la acción estatal. ${ }^{37} \mathrm{~A}$ pesar del potencial que tienen los PAN para incluir el contenido de los Principios Rectores en los sistemas jurídicos y políticos de los Estados, no se deben obviar las limitaciones que presentan. Por ejemplo, se ha demostrado que los PAN dependen de tendencias políticas, están sujetos a períodos gubernamentales y, sobre todo, no generan los efectos jurídicos deseados que requiere un cambio en la conducta empresarial (Cantú Rivera, 2020: 13).

Finalmente, la obligación de garantía abarca el deber de investigar, sancionar y garantizar el acceso a mecanismos de reparación. Este deber está estrechamente relacionado con el artículo 25.1 de la Convención Americana, que contiene la obligación de ofrecer a todas las personas sometidas a su jurisdicción un recurso judicial efectivo contra actos violatorios de sus derechos fundamentales. Uno de los principales retos en la región es la reparación efectiva a las personas que sufren abusos empresariales de derechos humanos. La confluencia de una serie de factores, como la falta de voluntad política, la captura corporativa, la corrupción, la falta de asistencia legal a víctimas, la politización del Poder Judicial, la estructura y el carácter transnacional de las empresas, entre otros, impiden el acceso efectivo a la justicia. A esto se suman otros obstáculos sustantivos y procesales, como la asimetría de recursos entre las empresas y las víctimas y los posibles riesgos que enfrentan las personas que interponen las denuncias (CIDH, 2019: párrs. 131-139).

Con base en los estándares mínimos del Pilar 3 de los Principios Rectores, la $\mathrm{CIDH}$ y su Redesca sugieren que los Estados deben implementar algunas medidas para proporcionar medios adecuados de reparación a las personas o grupos perjudicados y asegurar la rendición de cuentas de las empresas (CIDH, 2019: párr. 134). Los Estados no sólo deben tener en cuenta los recursos judiciales (administrativo, civil

36. Además de estos países que ya han publicado sus PAN, Argentina, Brasil, Guatemala, Honduras, México y Perú están en proceso de elaboración de sus propios planes. Sobre el contenido y el estado de los Planes en la región, véase el sitio de National Action Plans on Business and Humans Rights, disponible en https://globalnaps.org/.

37. Para un análisis sobre la efectividad de los PAN sobre empresas y derechos humanos como herramientas para dar efectividad al derecho internacional a nivel interno, véase Cantú Rivera (2017b). Asimismo, sobre los PAN, véase Muñoz Quick (2017) y Márquez Carrasco, Iglesias Márquez y Domínguez Díaz (2019), así como las referencias bibliográficas incluidas en ambos textos. 
o penal), sino también los mecanismos alternativos, como los extrajudiciales y no estatales, que puedan facilitar la rendición de cuentas de las empresas y la reparación a las víctimas. Estos mecanismos deben ser complementarios a los recursos judiciales y deben reunir al menos las características de garantía indicadas en los Principios Rectores: accesibilidad, predictibilidad, transparencia o equidad (Principio Rector 31) (CIDH, 2019: párrs. 143-144). Por ende, los recursos judiciales y extrajudiciales disponibles para las víctimas de abusos corporativos deben ser capaces de determinar la existencia de violaciones a derechos fundamentales, de reparar el daño causado y sancionar a las empresas responsables.

Algunas de las medidas propuestas por la CIDH y su Redesca para cumplir con este deber son, entre otras: el establecimiento de regímenes jurídicos de responsabilidad compartida de la empresa matriz o del grupo empresarial, el ofrecimiento de asistencia jurídica y otros sistemas de financiación a la parte demandante, la habilitación de demandas colectivas relacionadas con los derechos humanos y los litigios de interés público, el acceso a la información mediante legislación de divulgación obligatoria, la adopción de normas de procedimiento que permitan a las víctimas obtener la divulgación de pruebas en poder de la empresa acusada y la inversión de la carga de la prueba cuando la empresa demandada tenga conocimiento o control exclusivo de la totalidad o parte de los hechos y datos pertinentes para resolver una reclamación (CIDH, 2019: párrs. 134 y 139).

\section{La responsabilidad de las empresas de respetar los derechos humanos: Perspectiva interamericana}

Los altos niveles de impunidad corporativa y la asimetría normativa a nivel nacional e internacional respecto de la regulación de las empresas en materia de derechos humanos han planteado la necesidad de imponerles obligaciones directas en virtud del derecho internacional de los derechos humanos. Esto ha generado intensos debates que desafían las fronteras y los conceptos básicos del régimen jurídico internacional. Así, la doctrina iusinternacionalista avanza cada vez más en el desarrollo de la tesis que postula que los cambios y los retos que enfrenta la sociedad internacional, así como el beneficio y la participación de facto de las empresas en las relaciones internacionales, implican el reconocimiento de una subjetividad internacional parcial y limitada de las empresas, que es funcional y diferente a la de los Estados, que mantienen el papel primario en el derecho internacional. De esta manera, a las empresas no sólo se les atribuyen derechos, sino también obligaciones, cuya ejecución podría hacerse a nivel nacional (López Latorre, 2020: 82-83; Iglesias Márquez, 2019c: 100-101).

No obstante, la configuración actual del SIDH recoge en gran medida la visión clásica del derecho internacional (state-centered approach), caracterizada por una invisibilidad jurídica de las empresas, que no son consideradas como titulares directas 
de obligaciones internacionales y cuya virtualidad siempre depende de la mediación estatal. Por tanto, las obligaciones en materia de derechos humanos de las empresas que operan en la región derivan principalmente de los ordenamientos jurídicos internos que se constituyen en relación con los compromisos internacionales de los Estados. A diferencia del Sistema Europeo de Derechos Humanos, ${ }^{38}$ la Corte IDH, en su Opinión Consultiva OC-22/16, ha rechazado la titularidad de derechos de las personas jurídicas en el SIDH. Según la Corte, los derechos humanos pertenecen principalmente a las personas físicas y sólo se aplican a personas jurídicas para concretar los derechos humanos de las personas físicas que las integran. ${ }^{39}$ No obstante, este pronunciamiento no resuelve la cuestión sobre cuáles son las obligaciones y responsabilidades de las empresas en virtud de los instrumentos del SIDH, lo que plantea la posibilidad de que en un futuro la Corte IDH ejerza su competencia consultiva para aclarar y profundizar en este aspecto en concreto (Carrillo Santarelli, 2017: 103).

El informe de la CIDH y su Redesca aborda las limitaciones competenciales de los órganos del SIDH para pronunciarse sobre la responsabilidad de las empresas por abusos de derechos humanos. En este sentido, destacan que

existe un déficit en la adecuación o existencia de normas secundarias de derecho internacional que ayuden a fincar responsabilidad internacional a actores empresariales por violaciones de derechos humanos, con la excepción de aquéllas provenientes del derecho penal internacional y sin perjuicio de las iniciativas y discusiones vigentes y relevantes sobre un tratado internacional sobre el tema (CIDH, 2019: párr. 193).

Por ello, se vislumbra que el informe tiene un enfoque principalmente estatocéntrico, ya que se orienta a esclarecer el contenido y el alcance de las obligaciones estatales en materia de derechos humanos en el contexto de las actividades empresariales. No obstante, también aporta elementos claves para entender la responsabilidad de las empresas de respetar los derechos humanos a la luz de los instrumentos y estándares del SIDH.

La CIDH y su Redesca reconocen en el informe objeto del presente estudio que «las empresas tienen la capacidad fáctica de incidir de forma directa [en los derechos

38. En el Sistema Europeo de Protección de los Derechos Humanos, las empresas han interpuesto acciones ante el Tribunal Europeo de Derechos Humanos en las que alegan violaciones a derechos contenidos en la Convención Europea de Derechos Humanos. Principalmente alegan que los Estados han vulnerado sus derechos procesales, su derecho a la libertad de expresión y su derecho al respeto de sus bienes. Como antecedentes de estos supuestos se pueden destacar casos como Sunday Times con The United Kingdom (1979), Société Colas Est and Others con France (2004), GT Verein gegen Tierfabriken con Switzerland (2001) o Autronic AG con Switzerland (1990).

39. Corte Interamericana de Derechos Humanos, Opinión Consultiva OC-22/16, 26 de febrero de 2016, serie A núm. 22. 
humanos], y en algunos casos decisiva, en su realización» (CIDH, 2019: párr. 194). En el sistema de peticiones, aunque los órganos no se han pronunciado sobre la responsabilidad de las empresas, sí han analizado y considerado las consecuencias negativas de las acciones y actividades de las empresas sobre los derechos humanos. Por ejemplo, en el caso Sarayaku con Ecuador, la Corte IDH determinó que «los actos de la empresa, al pretender legitimar sus actividades de exploración petrolera y justificar sus intervenciones en el territorio sarayaku, dejaron de respetar las estructuras propias de autoridad y representatividad a lo interno y externo de las comunidades».40

Por tanto, la CIDH y su Redesca concluyen que las obligaciones internacionales en materia de derechos humanos dirigidas a los Estados pueden proyectar efectos en el comportamiento de las empresas en el mismo sentido que el Pilar 2 de los Principios Rectores sobre la responsabilidad de las empresas de respetar los derechos humanos (CIDH, 2019: párr. 181). Es decir, los Estados, en el cumplimiento efectivo de sus obligaciones de respeto y garantía de los derechos humanos, deben asegurar que las actividades empresariales se desarrollen de manera respetuosa con los derechos humanos. Como se analizó en los epígrafes anteriores, esto se logra a través del ejercicio de las competencias normativas, supervisoras, preventivas, investigativas y sancionatorias de los Estados. De esta manera, como señala la Corte IDH, se logra que «la obligación de respeto y garantía de los derechos humanos, que normalmente tiene sus efectos en las relaciones entre los Estados y los individuos sometidos a su jurisdicción, también proyecta sus efectos en las relaciones interindividuales».41

Se puede intuir entonces que el informe avanza de manera modesta y limitada en el reconocimiento de las obligaciones y responsabilidades de las empresas en virtud de los instrumentos interamericanos de derechos humanos. Este reconocimiento se ve respaldado por la - aún incipiente- jurisprudencia del SIDH respecto de esta cuestión en particular. Por ejemplo, en Kaliña y Lokono con Surinam, la Corte IDH, haciendo referencia a los Principios Rectores, se pronunció sobre el deber de las empresas de actuar de conformidad con el respeto y la protección de los derechos humanos, así como prevenir, mitigar y hacerse responsables por las consecuencias negativas de sus actividades sobre los derechos humanos. ${ }^{42}$

40. Sentencia del caso Pueblo Indígena Kichwa de Sarayaku con Ecuador, Corte Interamericana de Derechos Humanos, fondo y reparaciones, 27 de junio de 2012, serie C núm. 245, párrs. 194 y 209. Véase también caso Pueblos Kaliña y Lokono con Surinam, párr. 223.

41. Corte Interamericana de Derechos Humanos, Opinión Consultiva OC-18/03, 17 de septiembre de 2003, serie A núm. 18, párr. 146.

42. Caso Pueblos Kaliña y Lokono con Surinam, párr. 224. Incluso en la jurisprudencia del arbitraje internacional en la región existen importantes precedentes que avanzan en el reconocimiento de las obligaciones directas de las empresas en virtud del derecho internacional de los derechos humanos. En el caso Urbaser con Argenitna, el tribunal de arbitraje ha reconocido que las sociedades comerciales y las empresas internacionales se encuentran alcanzadas por las obligaciones resultantes del derecho inter- 
Asimismo, la posición de algunos Estados americanos en las negociaciones del tratado sobre empresas y derechos humanos en el seno del CDH supone también un respaldo a las obligaciones directas de las empresas en el SIDH. Países como Ecuador, Bolivia y Cuba propusieron en las etapas preliminares de las negociaciones que el futuro tratado incluyera obligaciones directas de carácter internacional para las empresas. El Estado de Ecuador, por ejemplo, señaló que el futuro instrumento vinculante debería incluir obligaciones para las empresas, como la diligencia debida hacia sus empleados y hacia las comunidades en las que operan. ${ }^{43}$ En un sentido similar, la delegación de Bolivia consideró que el tratado debería articular obligaciones, claras y directas para que las empresas transnacionales puedan ser consideradas responsables de prevenir, mitigar y compensar por los efectos de sus actividades en los derechos humanos, a fin de evitar la impunidad por sus acciones. ${ }^{44}$ Cuba, por su parte, indicó que uno de los objetivos del tratado debería ser delinear las principales obligaciones de las empresas transnacionales para prevenir, mitigar y compensar de forma efectiva las violaciones de derechos humanos que puedan ser cometidas como parte de sus operaciones. ${ }^{45}$

\section{Avances del Sistema Interamericano de Derechos Humanos en la protección de los derechos humanos frente a las actividades empresariales}

El informe de la CIDH y su Redesca presenta importantes e innovadores avances que son claves en la región para asegurar el disfrute de los derechos humanos en el contexto de las actividades empresariales. Los siguientes epígrafes se dedican al análisis de tres cuestiones que son consideradas en el informe como criterios fundamentales que deben ser abordados en los sistemas políticos y jurídicos de la región cuando se trate de la cuestión de empresas y derechos humanos. Estos son: personas defensoras de derechos humanos, cambio climático y extraterritorialidad.

nacional sobre los derechos humanos. Centro Internacional de Arreglo de Diferencias, caso ARB/o7/26 (Urbaser S.A. y Consorcio de Aguas Bilbao Bizkaia, Bilbao Bizkaia ur Partzuergoa contra Argentina) Laudo, 8 de diciembre de 2016, párr. 1159.

43. Delegación de Ecuador, «Mejorando la responsabilidad de las empresas transnacionales y otras empresas de negocios con respecto a los derechos humanos, incluyendo prevención, mitigación y remediación», Oficina del Alto Comisionado de las Naciones Unidas para los Derechos Humanos, 8 de julio de 2015, disponible en https://bit.ly/3gt/5Tt.

44. Delegación de Bolivia, «Estado Plurinacional de Bolivia, Panel VI: Sobre las obligaciones de empresas transnacionales y otras empresas», Oficina del Alto Comisionado de las Naciones Unidas para los Derechos Humanos, 8 de julio de 2015, disponible en https://bit.ly/2VWQRfd.

45. Delegación de Cuba, Intervención de la consejera Claudia Pérez Álvarez en la Primera sesión del Grupo de Trabajo Intergubernamental de composición abierta sobre un instrumento internacional jurídicamente vinculante sobre las empresas transnacionales y otras empresas con respecto a los derechos humanos», Oficina del Alto Comisionado de las Naciones Unidas para los Derechos Humanos, 8 de julio de 2015, disponible en https://bit.ly/3704CzS. 


\section{Personas defensoras de derechos humanos}

En América Latina es habitual que los impactos negativos de los proyectos y actividades empresariales sean un inminente llamado a la acción de las personas defensoras de derechos humanos que luchan por los intereses sociales y ambientales frente a los puramente económicos de las empresas. En el SIDH, se entiende que un defensor o defensora de derechos humanos es «toda persona que de cualquier forma promueva o procure la realización de los derechos humanos y las libertades fundamentales reconocidos a nivel nacional o internacional» (CIDH, 2006: párr. 13). Asimismo, existe una importante jurisprudencia consolidada que reconoce la labor de las personas defensoras, por ser fundamentales para el fortalecimiento de la democracia y el Estado de derecho. ${ }^{46}$

Las personas defensoras de derechos humanos tienen también un papel fundamental en el fomento del respeto de los derechos humanos por parte de las empresas, ya que se encargan de proteger la tierra y el medio ambiente, asegurar unas condiciones de trabajo justas y seguras, luchar contra la corrupción, respetar los derechos indígenas y lograr el desarrollo sostenible, entre otros. ${ }^{47}$ Este importante papel está reconocido en los Principios Rectores. Así, el Principio Rector 18 insta a las empresas a consultar a las personas defensoras como importantes expertas en derechos humanos. Mientras tanto, el comentario del Principio Rector 26 especifica que los Estados deben velar por la no obstrucción de las actividades legítimas de estas personas defensoras.

América Latina se ha convertido en una de las regiones más peligrosas y mortales para la defensa y la promoción de los derechos humanos en el contexto de las actividades empresariales. El riesgo es aún mayor para las mujeres defensoras de derechos humanos, que no solamente sufren de manera diferenciada y desproporcionada los impactos negativos de las empresas, sino que también están en el punto de mira por cuestionar el poder de las empresas en el marco del sistema capitalista patriarcal. ${ }^{48} \mathrm{En}$ países como Guatemala, Colombia, México, Brasil, Perú y Honduras se eleva cada vez más el número de casos de ataques físicos, intimidación, amenazas, criminalización e incluso de asesinatos por defender los derechos humanos de las consecuencias negativas relacionadas con los proyectos y actividades de las empresas. Por ejemplo, en

46. Véase la sentencia del caso Valle Jaramillo y otros con Colombia, fondo, reparaciones y costas, 27 de noviembre de 2008, serie C núm. 192; y sentencia del caso Defensor de derechos humanos y otros con Guatemala, excepciones preliminares, fondo, reparaciones y costas, 28 de agosto de 2014, serie C núm. 283.

47. Véase el Informe del relator especial sobre la situación de los defensores de los derechos humanos, $\mathrm{A} / 72 / 170,19$ de julio de 2017, párr. 1 .

48. Sobre el sistema capitalista patriarcal, véase Ballester Buigues (2010) y Elguero Altner y Moreno Velador (2016). 
Guatemala, los asesinatos de las personas defensoras aumentaron de 3 en 2017 a 16 en 2018, lo que lo convierte en el país más peligroso en 2018 (Global Witness, 2019: 9). En estos casos, las empresas suelen estar implicadas, directa o indirectamente, en los ataques, sobre todo las que pertenecen a sectores como la minería, la agroindustria, el petróleo, el gas, el carbón y la construcción de presas. ${ }^{49}$

Por lo anterior, la CIDH y su Redesca consideran que el derecho a defender los derechos humanos es un criterio interamericano fundamental que debe considerarse e incluirse en los marcos normativos y políticos desarrollados por los Estados en el ámbito de empresas y derechos humanos. En este sentido, el informe de la $\mathrm{CIDH}$ y su Redesca, en primer lugar, reafirma que los Estados son los principales responsables en garantizar que se prevengan, identifiquen y sancionen las violaciones contra las personas defensoras de derechos humanos (CIDH, 2019: párr. 327). En segundo lugar, el informe avanza en la consolidación del deber de los Estados americanos de establecer «un marco legal claro, que prevea sanciones contra empresas que están involucradas en la criminalización, estigmatización, abusos y violaciones contra quienes defienden los derechos humanos, incluyendo empresas privadas de seguridad y contratistas que actúan en nombre de la empresa involucrada» (CIDH, 2019: párr. 47). Finalmente, en el marco de las instituciones internacionales de financiamiento, en el informe se sugiere a los Estados la implementación de sistemas independientes y participativos, en los que se tengan en cuenta las consideraciones de las personas defensoras de derechos humanos en el momento de otorgar el financiamiento (CIDH, 2019: párr. 317).

\section{Cambio climático}

El cambio climático es uno de los mayores retos a los que se expone América Latina y el Caribe, debido a la alta vulnerabilidad frente a sus efectos adversos, que tienen especial repercusión en el disfrute de diversos derechos humanos. La alta vulnerabilidad de la región al cambio climático ha llevado a que la Asamblea General de la OEA reconozca de manera expresa que «el cambio climático genera impactos negativos en todo el hemisferio provocando la degradación de la calidad de vida y del medio ambiente para las generaciones presentes y futuras»..$^{\circ}$

La Corte IDH, por su parte, también ha reconocido de manera cautelosa en su Opinión Consultiva 23/17 que «los efectos adversos del cambio climático afectan el

49. Informe del relator especial sobre la situación de los defensores de los derechos humanos, A/72/170, 19 de julio de 2017, párrs. 16 y 54.

50. Véase Organización de los Estados Americanos, AG/RES. 2818 (XLIV-O/14), El Cambio Climático en el Marco del Desarrollo Sostenible en el Hemisferio, 4 de junio de 2014; Resolución AG/RES. 2429 (XXXVIIIO/o8), Derechos Humanos y Cambio Climático en las Américas, 3 de junio de 2008. 
goce efectivo de los derechos humanos». ${ }^{51}$ No obstante, ha perdido una importante oportunidad de esclarecer, a la luz de los estándares interamericanos, el contenido y el alcance de las obligaciones (extraterritoriales) de los Estados en materia de derechos humanos relacionadas con los efectos transfronterizos del cambio climático. Es decir, las emisiones de gases de efecto invernadero (GEI) - o incluso la falta de ambición climática- de un Estado pueden afectar el disfrute de los derechos humanos reconocidos en el SIDH de personas en el territorio de otro Estado. Esto se enmarca dentro de la cuestión planteada por la Corte IDH en su Opinión Consultiva 23/17 sobre en qué medida, de acuerdo con lo estipulado en el artículo 1.1 de la Convención Americana, debería considerarse que una persona, aunque no se encuentre en el territorio de un Estado parte, podría estar sujeta a la jurisdicción de dicho Estado en el marco del cumplimiento de obligaciones en materia ambiental. En este sentido, en 2004, la Conferencia Circumpolar Inuit, en nombre de todas las regiones árticas de Estados Unidos y Canadá, presentó una petición ante la CIDH en la que se alegó la responsabilidad de Estados Unidos por violaciones de derechos humanos protegidos por la Declaración Americana. Según los peticionarios, el Estado incumplía sus obligaciones en materia de derechos humanos debido a la desregulación de ciertas actividades emisoras de GEI que afectan el modo de vida de los pueblos indígenas de las regiones árticas. La petición del caso inuit fue rechazada por la $\mathrm{CIDH}$ debido a que la información no era suficiente para determinar el nexo causal entre la acción del Estado y las vulneraciones de derechos humanos asociados al cambio climático. No obstante, es un precedente importante que pone de manifiesto la necesidad de que el SIDH siga explorando la relación entre cambio climático y derechos humanos para avanzar en la agenda de justicia climática desde la perspectiva regional.

En el sistema universal, el relator especial de las Naciones Unidas sobre derechos humanos y medio ambiente ha señalado que las obligaciones de derechos humanos son aplicables no solo a las decisiones relativas al grado de protección del clima, sino también a las medidas de mitigación y adaptación adoptadas a los efectos de la protección. Esto implica, por tanto, que los Estados tienen obligaciones positivas de medidas destinadas a la protección de los derechos humanos frente a los impactos del cambio climático. En este sentido, los Estados deben controlar las actividades de las empresas que contribuyen al cambio climático mediante la adopción y aplicación de marcos jurídicos e institucionales para proteger de los daños ambientales que interfieran o puedan interferir en el disfrute de los derechos humanos y para responder a todas las violaciones de los derechos humanos causadas por la degradación ambiental, incluido el menoscabo de los derechos humanos en relación con el cambio climático. ${ }^{52}$

51. Corte Interamericana de Derechos Humanos, Opinión Consultiva OC-23/17, 15 de noviembre de 2017, serie A núm. 23, párr. 47.

52. Véase el Informe del relator especial sobre la cuestión de las obligaciones de derechos huma- 
La relación entre empresas, derechos humanos y cambio climático es una cuestión poco explorada todavía, pero que recibe una creciente atención (Iglesias Márquez, 2020: 101-107). En este sentido, el informe de la CIDH y su Redesca complementa los estándares internacionales en materia de empresas y derechos humanos, que no siempre abordan explícitamente el cambio climático. Lo hace a través de una serie de orientaciones y recomendaciones que los Estados deben seguir para dar cumplimiento a sus obligaciones de respetar y garantizar, con el objetivo de asegurar que el comportamiento y las relaciones comerciales de las empresas no continúen contribuyendo al cambio climático.

En relación con lo anterior, es posible identificar en el informe de la CIDH y su Redesca los siguientes estándares respecto al ámbito de empresas y derechos humanos en el contexto de la crisis climática. En primer lugar, en cumplimiento de la obligación estatal de regular efectivamente a actores privados, los Estados deben asegurar que cualquier política pública y marco normativo que se implemente en relación con la mitigación, adaptación y resiliencia al cambio climático debe hacerse con un enfoque de derechos e incluir los impactos y vulneraciones producidas por las empresas, incluyendo a los agentes de financiamiento e inversión. En segundo lugar, los Estados tienen la obligación positiva de garantizar que empresas públicas y privadas generadoras de emisiones de GEI las reduzcan y rindan cuentas por el perjuicio que puedan ocasionar al clima (CIDH, 2019: párrs. 246-247).

En tercer lugar, los Estados deben incrementar sus acciones hacia una política de transición hacia fuentes de energía renovables y limpias, mediante estrategias de desarrollo con bajas emisiones en las que se respeten los derechos humanos. Esto implica evitar los incentivos financieros y fiscales para actividades que no se enmarquen dentro de los mecanismos de la reducción de la huella de carbono, de modo de crear una medida de mitigación que prevenga mayor riesgo y daño. Por último, en relación con el Pilar 2 de los Principio Rectores, los Estados deben garantizar el acceso a la justicia y a la reparación del daño en materia climática. ${ }^{33}$ Para ello, deben contar con mecanismos accesibles, asequibles, oportunos y efectivos para impugnar aquellas acciones u omisiones que puedan afectar los derechos humanos por el cambio climático y obtener la reparación de los daños derivados de los riesgos climáticos y de las políticas que se tomen al respecto, ya sea que estas acciones provengan del Estado o de las empresas (CIDH, 2019: párrs. 244, 248 y 250-251).

nos relacionadas con el disfrute de un medio ambiente sin riesgos, limpio, saludable y sostenible, A/ HRC/31/52, 1 de febrero de 2016, párrs. 23-32 y 66-67.

53. Sobre la litigación climática en contra de las empresas, véase Iglesias Márquez (2019d). 


\section{Extraterritorialidad}

Uno de los temas más controversiales en el ámbito de empresas y derechos humanos es el ejercicio de la jurisdicción extraterritorial de los Estados (Cantú Rivera, 2019), a pesar de que el derecho internacional contemporáneo no lo prohíbe para regular y hacer efectiva la responsabilidad de las empresas domiciliadas o registradas en su territorio o bajo su control, siempre que haya una base jurisdiccional reconocida (Augenstein y Kinley, 2013: 276-277). Diversos órganos de derechos humanos han recomendado a algunos Estados la adopción de medidas para impedir que las empresas registradas en su jurisdicción cometan abusos en el extranjero. Por ejemplo, el Comité de Derechos Humanos ha alentado a Canadá a que establezca claramente que todas las empresas domiciliadas en su territorio o bajo su jurisdicción deben respetar en todas sus actividades -incluidas las que se llevan a cabo en el extranjero- la normativa de los derechos humanos de conformidad con el Pacto Internacional de Derechos Civiles y Políticos (CCPR/C/CAN/CO/6).

El aumento de la cooperación sur-sur fomenta el comercio y los flujos de inversión entre los Estados de la región, lo que a su vez favorece las estrategias de desterritorialización y descentralización de las actividades empresariales..$^{54}$ Por tanto, las empresas latinoamericanas operan en diversos países de la región con un alto potencial de generar graves impactos sobre los derechos humanos y el medio ambiente. Al respecto, destacan en la región los impactos negativos sobre los pueblos indígenas y comunidades afrodescendientes derivados de las actividades extractivas de empresas con origen en un tercer Estado (CIDH, 2015c: párrs. 77-88). Por ejemplo, el caso de la empresa canadiense Hudbay Minerals, acusada de complicidad por la comisión de violaciones de derechos humanos a las comunidades indígenas en Guatemala. ${ }^{55}$

Por lo anterior, el ejercicio de la jurisdicción — prescriptiva y jurisdiccional- extraterritorial es esencial en la región. No obstante, esta cuestión ha sido abordada de manera incipiente por los órganos políticos de la OEA (Cerqueira, 2015: 18-21). En este sentido, el informe sobre empresas y derechos humanos presenta un nuevo panorama y nuevas oportunidades para el desarrollo de esta cuestión en la región. Según la CIDH y su Redesca, en el contexto de la sociedad altamente globalizada, la aplicación extraterritorial de los sistemas políticos y jurídicos nacionales en materia de empresas y derechos humanos constituye un elemento clave, ya que se ajusta a las complejas formas de organización y operaciones transnacionales de las empresas

54. Anabel Gonzalez, Christine Zhenwei Qiang y Bertram Boie, «South-South investment: Development opportunities and policy agenda», World Bank Blog, 28 de abril de 2015, disponible en https://bit. ly/2Lopc 4 K.

55. Véase «Perfil de las demandas judiciales contra Hudbay por actividades en Guatemala», Centro de Información sobre Empresas y Derechos Humanos, 12 de julio de 2013, disponible en https://bit. ly/39YU3 Pq. 
(CIDH, 2019: párr. 52). La Corte IDH ha interpretado que el concepto de jurisdicción bajo el artículo 1.1 de la Convención Americana abarca cualquier situación en la que un Estado ejerza autoridad o control efectivo sobre las personas, dentro o fuera de su territorio. Por ello, en relación con lo dispuesto en la Observación General 24 del Comité de Naciones Unidas de Derechos Económicos, Sociales y Culturales, ${ }^{56}$ los Estados del SIDH están obligados a adoptar todas las medidas necesarias para evitar que las actividades desarrolladas en su territorio o bajo su control afecten los derechos de las personas dentro o fuera de su territorio. No obstante, la Corte también ha delimitado que el ejercicio de la jurisdicción de un Estado fuera de su territorio es una situación excepcional que debe analizarse en cada caso concreto y de manera restrictiva. ${ }^{57}$

La CIDH y su Redesca, por tanto, se muestran partidarias del ejercicio de la jurisdicción extraterritorial de los Estados en relación con la actuación de las empresas, con base en los conceptos de autoridad y control efectivo. Asimismo, añaden la capacidad de influencia de los Estados en el comportamiento de las empresas para justificar el ejercicio de la jurisdicción extraterritorial. En línea con los pronunciamientos de diversos órganos del sistema universal, ${ }^{58}$ la CIDH y su Redesca consideran que los Estados deben adoptar medidas para regular, supervisar e investigar el comportamiento de las empresas domiciliadas en su jurisdicción que afecten el disfrute de los derechos humanos en terceros Estados, siempre y cuando no se afecte el principio de soberanía o el principio de igualdad de todos los Estados (CIDH, 2015C: párr. 153).59

56. El Comité de Derechos Económicos, Sociales y Culturales justifica el ejercicio de la jurisdicción extraterritorial cuando un Estado parte puede influir en situaciones que se producen fuera de su territorio, de conformidad con los límites impuestos por el derecho internacional, controlando las actividades de las empresas domiciliadas en su territorio o bajo su jurisdicción y, por lo tanto, contribuir al disfrute efectivo de los derechos económicos, sociales y culturales fuera de su territorio nacional. Véase Comité de Derechos Económicos, Sociales y Culturales, Observación General 24, de 2017, sobre las obligaciones de los Estados en virtud del Pacto Internacional de Derechos Económicos, Sociales y Culturales en el contexto de las actividades empresariales, 10 de agosto de 2017, E/C.12/GC/24, párr. 28.

57. Opinión Consultiva OC-23/17, 15 de noviembre de 2017, serie A núm. 23, párr. 104. Sobre la aplicación extraterritorial de las obligaciones de los Estados contenidas en los instrumentos interamericanos, véase Cassel (2004).

58. Véase, por ejemplo, Comité de los Derechos del Niño, Observación General 16, CRC/C/GC/16, 17 de abril de 2013, párr. 43; Comité para la Eliminación de la Discriminación contra la Mujer, Observaciones Finales (Suiza), CEDAW/C/CHE/CO/4-5, 25 de noviembre de 2016, párr. 41; Comité para la Eliminación de la Discriminación contra la Mujer, Recomendación General 37, CEDAW/C/GC/37, 13 de marzo de 2018, párrs. 43-51.

59. En este sentido, el Comité Derechos Económicos, Sociales y Culturales ha señalado que «las obligaciones extraterritoriales surgen cuando un Estado parte puede influir en situaciones que se producen fuera de su territorio, de conformidad con los límites impuestos por el derecho internacional, controlando las actividades de las empresas domiciliadas en su territorio y/o bajo su jurisdicción y, por lo tanto, 
Eso implica el deber de diseñar instituciones y disposiciones jurídicas con efectos extraterritoriales que disminuyan los riesgo previsibles de abusos o violaciones de derechos humanos en terceros Estados, así como la creación o el fortalecimiento de recursos efectivos para que las víctimas en dichos Estados puedan acceder a la justicia y a una debida reparación de acuerdo con el derecho internacional de los derechos humanos (CIDH, 2019: párr. 168). La CIDH y su Redesca aclaran que lo anterior no implica una disminución de las obligaciones de los Estados receptores donde tienen lugar los abusos de derechos humanos, sino más bien implica un deber de cooperar entre los Estados para no obstaculizar el disfrute de los derechos humanos en otros países y, sobre todo, para evitar situaciones de impunidad (CIDH, 2019: párrs. 169, 172 y 174$)$.

\section{Conclusiones}

Los impactos negativos de las empresas sobre el disfrute de los derechos humanos constituyen una de las externalidades más evidentes de la economía capitalista en las Américas. Las acciones - individuales y colectivas- de los Estados de la región para garantizar el respeto y la garantía de los derechos humanos en el contexto de las actividades empresariales se han mostrado insuficientes hasta el momento. Sin embargo, ante esta situación, los Estados americanos y la OEA, a través de los órganos del SIDH, parecen estar despertando del largo letargo generado por la necesidad de alcanzar un desarrollo económico que los entorpecía y los incapacitaba para hacer frente a los abusos corporativos que tienen lugar a lo largo del continente.

En los últimos tiempos, los esfuerzos globales y universales por promover una conducta empresarial responsable han tenido una especial resonancia en las Américas. Así, la OEA, mediante sus órganos políticos y consultivos, ha profundizado y avanzado de manera más activa en el debate sobre empresas y derechos humanos para asegurar el respeto de los derechos humanos en el contexto de las actividades empresariales, teniendo en cuenta las características particulares de la región. Si bien en el seno de la organización por el momento no se han adoptado instrumentos regionales en la materia, como en el caso de la Unión Europea, sí que se han dado los primeros pasos que marcan una hoja de ruta para cambiar el paradigma del business as usual y promover una conducta empresarial responsable. Sobre todo, se vislumbra la configuración de una posición regional sobre la conducta empresarial deseable, que permite avanzar en la refinación y modulación de los estándares universales en materia de empresas y derechos humanos para que respondan a las necesidades en la

contribuir al disfrute efectivo de los derechos económicos, sociales y culturales fuera de su territorio nacional». Véase Comité de Derechos Económicos, Sociales y Culturales, Observación General 24, E/C.12/ GC/24, 10 de agosto de 2017, párr. 28. 
región de un desarrollo socioeconómico que sea respetuoso con los derechos humanos y el medio ambiente. De hecho, esta posición incluso puede ser trasladada a las negociaciones del tratado en el seno del CDH.

En esta línea se enmarca el informe encargado por la Asamblea General de la OEA a la CIDH sobre los estándares interamericanos en materia de empresas y derechos humanos analizado en el presente artículo. Éste, por un lado, sienta las bases para avanzar en un plan regional que incluya acciones vinculantes y no vinculantes para prevenir y reparar abusos corporativos a la luz de otros estándares interamericanos de derechos humanos. Estas acciones deben tomar en consideración cuestiones como la situación de las personas defensoras de derechos humanos, el cambio climático o las obligaciones extraterritoriales de los Estados, que son temas que han sido abordados de manera cautelosa en los foros internacionales, pero que son de especial relevancia en la región. Por ello, son considerados criterios fundamentales en la materia.

Por otro lado, este informe cristaliza, armoniza y consolida los esfuerzos políticos y normativos individuales de los Estados americanos que promueven una conducta empresarial responsable. En este sentido, el informe orienta a los Estados a adoptar, o en su defecto, a alinear sus sistemas políticos y normativos en materia de empresas y derechos humanos para que cumplan con los requisititos mínimos para dar cumplimiento a sus obligaciones de respetar y garantizar los derechos reconocidos en los instrumentos interamericanos de derechos humanos.

Por último, aunque el informe no está dirigido directamente a las empresas, genera mayores expectativas en el comportamiento de estos actores en la región, ya que sus actividades se someten a un considerable escrutinio por parte de los Estados y otros actores de interés en el ámbito de empresas y derechos humanos. Asimismo, las víctimas de abusos corporativos o las personas defensoras de derechos humanos pueden invocar los estándares identificados y desarrollados por la CIDH y su Redesca en posibles acciones judiciales, lo que genera una mayor presión para los Estados a la hora de promover cambios en la cultura empresarial.

\section{Reconocimiento}

El presente estudio ha sido elaborado en el marco del proyecto de investigación «Gobernanza y aplicación de la responsabilidad social empresarial en la Unión Europea» (DER2017-85834-R) y del Grupo de Investigación SEJ 055, «Nuevos sujetos, nuevos derechos, nuevas responsabilidades: derechos humanos en la sociedad global» de la Universidad de Sevilla, España. Asimismo, parte de la investigación ha sido elaborada en el marco de colaboración con el Instituto de Derechos Humanos y Empresas de la Universidad de Monterrey, México. 


\section{Referencias}

Augenstein, Daniel y David Kinley (2013). «When human rights "responsibilities" become "duties": The extra-territorial obligations of states that bind corporations». En Surya Deva y David Bilchitz (editores), Human rights obligations of business: Beyond the corporate responsibility to respect? (pp. 271-294). Cambridge: Cambridge University Press.

BACKER, Larry Catá (2017). «The human rights obligations of State-owned enterprises (SOEs): Emerging conceptual structures and principles in national and international law and policy». Vanderbilt Journal of Transnational Law, 51: 827-886. Disponible en https://bit.ly/3m4B1JS.

BALlester Buigues, Irene (2010). «Imágenes extremas contra el capitalismo patriarcal globalizador: Combatividad y resistencia». Arte y Políticas de Identidad, 3: 4158. Disponible en https://bit.ly/3n6Ifis.

Cantú Rivera, Humberto (2017a). Derechos humanos y empresas: Reflexiones desde América Latina. San José: IIDH.

-. (2017b). «Planes de acción nacional sobre empresas y derechos humanos: Sobre la instrumentalización del derecho internacional en el ámbito interno». Anuario Mexicano de Derecho Internacional, 17: 113-144. DOI: 10.22201/ iij.24487872e.2017.17.11033.

-. (2018). «Business and human rights in the Americas: Defining a Latin American route to corporate responsibility». En Jernej Letnar Cernic y Nicolás Carrillo-Santarelli (editores), The future of business and human rights: Theoretical and practical considerations for a UN Treaty. Cambridge, Antwerp, Portland: Intersentia.

-. (2019). «Extraterritorial obligations of States in the business and human rights context». En Matthew Mullen (editor), Navigating a new era of business and human rights: Challenges and opportunities under the UNGPs (pp. 214-220). Article 30.

-. (2020). Herramienta de diagnóstico sobre la implementación de las obligaciones internacionales de derechos humanos en el contexto de la actividad empresarial. San José: IIDH.

Carrillo Santarelli, Nicolás (2017). «La promoción y el desarrollo de la protección de los derechos humanos frente a abusos empresariales en el sistema interamericano». En Humberto Cantú Rivera (editor), Derechos humanos y empresas: Reflexiones desde América Latina (pp. 87-118). San José: IIDH.

Carrillo-Santarelli, Nicolás y Carlos Arévalo-Narváez (2017). «The discursive use and development of the guiding principles on business and human rights in Latin America». International Law: Revista Colombiana de Derecho Internacional, 30: 61-118. DOI: 10.11144/javeriana.il15-30.dudg.

CAssel, Douglass (2004). «Extraterritorial application of Inter-American human 
rights instruments». En Fons Commans y Menno Kamminga (editores), Extraterritorial application of human rights treaties (pp. 175-182). Amberes: Intersentia.

Cerqueira, Daniel (2015). «La atribución de responsabilidad extraterritorial por actos de particulares en el sistema interamericano: Contribuciones al debate sobre empresas y derechos humanos». Aportes DPLF: Revista de la Fundación para el Debido Proceso (DPLF), 8 (20): 18-21.

$\mathrm{CIDH}$, Comisión Interamericana de Derechos Humanos (2006). Informe sobre la situación de las defensoras y defensores de los derechos humanos en las Américas. Washington D. C.: CIDH.

-. (2007). El acceso a la justicia como garantía de los derechos económicos, sociales y culturales. Estudio de los estándares fijados por el sistema interamericano de derechos humanos. Washington D. C.: CIDH.

-. (2015a). Estándares jurídicos vinculados a la igualdad de género y a los derechos de las mujeres en el sistema interamericano de derechos humanos: desarrollo y aplicación. Actualización del 2011-2014. Washington D. C.: CIDH.

-. (2015b). Universalización del sistema interamericano de derechos humanos. Washington D. C.: CIDH.

-. (2015c). Pueblos indígenas, comunidades afrodescendientes y recursos naturales: Protección de derechos humanos en el contexto de actividades de extracción, explotación y desarrollo. Washington D. C.: CIDH.

-. (2017). Plan estratégico 2017-202. Washington D. C.: CIDH.

-. (2019). Informe empresas y derechos humanos: Estándares interamericanos. Washington D. C.: CIDH.

De Casas, C. Ignacio (2019). «¿Qué son los estándares de derechos humanos?»Revista Internacional de Derechos Humanos, 9 (2): 291-301.

DPLF, Fundación para el Debido Proceso (2014). El impacto de la minería canadiense en América Latina y la responsabilidad de Canadá. Washington D. C.: DPLF.

Elguero Altner, Alejandra y Octavio Humberto Moreno Velador (2016). «La construcción del patriarcado en el capitalismo: El caso del Protocolo de Palermo». Bajo el Volcán, 15 (23): pp. 53-74. Disponible en https://bit.ly/37Qiopv.

Global Witness (2019). ¿Enemigos del Estado? De cómo los gobiernos y las empresas silencian a las personas defensoras. Londres: Global Witness.

GonZA, Alejandra (2016). «Integrating business and human rights in the Inter-American human rights system». Business and Human Rights Journal, 1 (2): 357-365. DOI: $10.1017 / \mathrm{bhj} .2016 .18$.

Gos, Tatiana (2016). «La "responsabilidad de respetar" los derechos humanos y el establecimiento del deber de debida diligencia como una obligación legal para las industrias extractivas: Desafíos y oportunidades en las Américas». American University International Law Review, 32 (4): 859-893. Disponible en https://bit. ly/341gj7L. 
Hernández Zubizarreta, Juan, Mikel de la Fuente Lavín, Andrea de Vicente Arias y Koldo Irurzun Ugalde (2013). Empresas transnacionales en América Latina: Análisis y propuestas del movimiento social y sindical. Madrid-Bilbao-San Sebastian: OMAL-HEGOA-UPV/EHU.

Hitters, Juan Carlos (2008). «¿Son vinculantes los pronunciamientos de la Comisión y de la Corte Interamericana de Derechos Humanos? (Control de constitucionalidad y convencionalidad)». Revista Iberoamericana de Derecho Procesal Constitucional, 10: 131-156. Disponible en https://bit.ly/2W9jLsP.

IgLESIAS MÁRQUEZ, Daniel (2019a). «Hacia un tratado sobre empresas y derechos humanos: viejos debates, nuevas oportunidades». Deusto Journal of Human Rights, 4: 145-176. Disponible en https://bit.ly/3oHjVUg.

-. (2019b). The institutionalisation of initiatives to promote business respect for human rights. Barcelona: ICIP.

-. (2019c). «Las obligaciones de las empresas en virtud del derecho internacional: Retos y oportunidades en materia de empresas y derechos humanos». En Ricardo Abello-Galvis y Walter Arévalo-Ramírez (editores), Derechos humanos y empresas y Sistema Interamericano de Derechos Humanos: Reflexiones y diálogos (pp. 67104). Bogotá: Editorial Universidad del Rosario.

-. (2019d). «La litigación climática en contra de los carbon majors en los Estados de origen: Apuntes desde la perspectiva de empresas y derechos humanos». Revista Electrónica de Estudios Internacionales, 37: 1-37. Disponible en https://bit. ly/3m6TTrV.

-. (2020). «Empresas, derechos humanos y el régimen internacional del cambio climático: La configuración de las obligaciones climáticas para las empresas». Anuario Mexicano de Derecho Internacional, 20: 85-134. DOI: 10.22201/ iij.24487872e.2020.20.14472.

López LatorRe, Andrés Felipe (2020). «In defence of direct obligations for businesses under international human rights law». Business and Human Rights Journal, 5 (1): 56-83. DOI: 10.1017/bhj.2019.27.

Márquez Carrasco, Carmen, Daniel Iglesias Márquez y Francisco Domínguez Díaz (2019). El I Plan de Acción Nacional sobre Empresas y Derechos Humanos de España evaluación, seguimiento y propuestas de revisión. Cizur Menor: Aranzadi.

Mijares PeÑa, Susana (2014). «Human rights violations by Canadian companies abroad: Choc v Hudbay Minerals Inc.». Western Journal of Legal Studies, 5 (1): 1-21. Disponible en https://bit.ly/3gxQtgF.

Molina Vergara, Marcela (2018). «Estándares jurídicos internacionales: Necesidad de un análisis conceptual». Revista de Derecho Universidad Católica del Norte, 25 (1): 233-256. DOI: 10.4067/So718-97532018000100233.

Morris, Daniel (2020). Impulsar el cambio a través de la contratación pública: Herramientas de derechos humanos para profesionales y responsables de la formulación 
de políticas de contratación pública. Copenhague: Instituto Danés de Derechos Humanos.

Muñoz Quick, Paloma (2017). «Buscando la reconciliación: Planes de acción para lograr la transición». En Humberto Cantú Rivera (editor), Derechos humanos y empresas: Reflexiones desde América Latina (pp. 313-338). San José: IIDH.

O'Donnell, Daniel (1989). Protección internacional de los derechos humanos. Lima: Comisión Andina de Juristas.

SAlazar, Katya (2015). «Empresas y derechos humanos: ¿Un nuevo desafío para la OEA?» Aportes DPLF: Revista de la Fundación para el Debido Proceso (DPLF), 8 (20): 9-11.

SCHÖNSTEINER, Judith (2019). "Attribution of State responsibility for actions or omissions of States on owned enterprises in human rights matters». University of Pennsylvania Journal of International Law, 40 (4): 895-936. Disponible en https:// bit.ly/2JVY38G.

Solanes, Miguel (1995). «La privatización de los servicios públicos de agua». Revista de la Cepal, 56: 149-162. Disponible en https://bit.ly/zaoYIka.

Villalta Vizcarra, Elizabeth (2020). «Responsabilidad social de las empresas en situaciones de riesgos y amenazas». Anuario Hispano-Luso-Americano de Derecho Internacional, 24: 185-200. Disponible en https://bit.ly/3ozpBzs.

WALLERSTEIn, Immanuel (2005). Análisis de sistemas-mundo: Una introducción. Ciudad de México: Siglo XXI.

\section{Sobre el autor}

Daniel Iglesias MÁrquez es doctor en Derecho cum laude por la Universidad Rovira i Virgili, España. Licenciado en Derecho por la Universidad de Colima, México. Máster en Derecho Ambiental por la Universidad Rovira i Virgili y Máster en Gobernanza Global y Derechos Humanos por la Universidad Castilla-La Mancha, España. Es investigador postdoctoral «Juan de la Cierva» del Departamento de Derecho Internacional Público y Relaciones Internacionales de la Universidad de Sevilla, España, y miembro del Consejo de la Academia Latinoamericana de Derechos Humanos y Empresas de la Global Business and Human Rights Scholars Association. Su correo electrónico es dimarquez@us.es. (1D) https://orcid.org/oooo-0003-2759-3064. 
El Anuario de Derechos Humanos es una publicación semestral de referencia y consulta en materia de derechos humanos y campos afines. Busca ser un espacio de discusión de los temas centrales en el ámbito nacional e internacional sobre derechos humanos. Es publicado desde 2005 por el Centro de Derechos Humanos de la Facultad de Derecho de la Universidad de Chile.

\author{
EDITORA \\ Claudia Iriarte Rivas \\ ciriarter@derecho.uchile.cl \\ SITIO WEB \\ anuariocdh.uchile.cl \\ CORREO ELECTRÓNICO \\ anuario-cdh@derecho.uchile.cl \\ LICENCIA DE ESTE ARTÍCULO \\ Creative Commons Atribución Compartir Igual 4.o Internacional
}

\author{
\% \\ La edición de textos, el diseño editorial \\ y la conversión a formatos electrónicos de este artículo \\ estuvieron a cargo de Tipográfica \\ (www.tipografica.io)
}

